\title{
XY Female with Complete Androgen Insensitivity Syndrome with Bilateral Inguinal Hernia
}

\author{
Nair Rema V. • Bhavana S.
}

Received: 12 October 2009/Accepted: 28 May 2012/Published online: 22 February 2013

(C) Federation of Obstetric \& Gynecological Societies of India 2013

\section{Introduction}

The complete androgen insensitivity syndrome, previously called testicular feminization syndrome, is an X-linked recessive rare disorder. The individual is phenotypically female and genotypically male: a male pseudohermaphrodite. The individuals are reared as girls and the condition is suspected when the individual is evaluated for primary amenorrhea, infertility, or when unilateral/bilateral inguinal hernia is diagnosed in girls.

\section{Case Report}

A 30-year-old married lady presented to the gynecological OPD with complaints of swelling in the groin on both the sides for the past 4 months. The swelling increased on coughing, straining and reduced on lying down. There was no history suggestive of obstruction/irreducibility. She had not attained menarche. She was married to a widower for the past 8 years. The husband had 2 children from the first wife. They had no problems during sexual intercourse. She had 3 siblings, all of whom were married and had children.

Nair R. V., Director · Bhavana S. (凹), Assistant Professor Sree Mookambika Institute of Medical Sciences Campus, Velayudhan Pillai Memorial Hospital Complex, Qr. No. 1, Padanilam, Kulasekharam, Kanyakumari District 629161, Tamil Nadu, India

e-mail: bhavana_yajat@yahoo.com
On examination, she was a tall, well-built, and wellnourished female. Her details were as follows: height$167 \mathrm{~cm}$; weight $-74 \mathrm{~kg}$; arm span-165 cm; thyroidnormal; secondary sexual characters-axillary hair and pubic hair absent; breasts-Tanner3 (well developed with pale areolae, immature nipple (Fig. 1)).The abdomen was soft. The external genitalia were female (Fig. 2).On per speculum examination, a 4-cm-long blind vaginal pouch was seen. The inguinal region on the right and left side showed pyriform non-tender swellings of $2.5 \times 2.5 \mathrm{~cm}^{2}$ and $2 \times 2 \mathrm{~cm}^{2}$, respectively, descending till the upper part of the labia majora. The swellings were felt above and medial to the pubic tubercle and the cough impulse was present. Thus, clinically, bilateral inguinal hernia was diagnosed.

The Sonography showed absent uterus and ovaries, oval hypoechoic structures on both sides of the inguinal region, suggestive of bilateral inguinal hernia. The abdominal organs were normal. Laparoscopy confirmed the absence of the uterus and ovaries.

The chromosomal analysis, GTG banded karyotyping showed 46 XY pattern.

The blood investigations found the following: Serum Testosterone $3.04 \mathrm{ng} / \mathrm{ml}$ (male range $1.8-9.0 \mathrm{ng} / \mathrm{ml}$, female $0.2-1.2 \mathrm{ng} / \mathrm{ml}$ ); LH $21.04 \mathrm{mIU} / \mathrm{ml}$ (male age 20-70 years: $1.5-9.3 \mathrm{mIU} / \mathrm{ml},>70$ years $1.3-34.6 \mathrm{mIU} / \mathrm{ml})$; FSH $2.53 \mathrm{mIU} / \mathrm{ml}$ (male 1.4-18.1 mIU/ml); Serum Estradiol $55.17 \mathrm{pg} / \mathrm{ml}$ (male 11.6-42.0 pg/ml). All the blood tests were of the male range and in accordance with CAIS. 


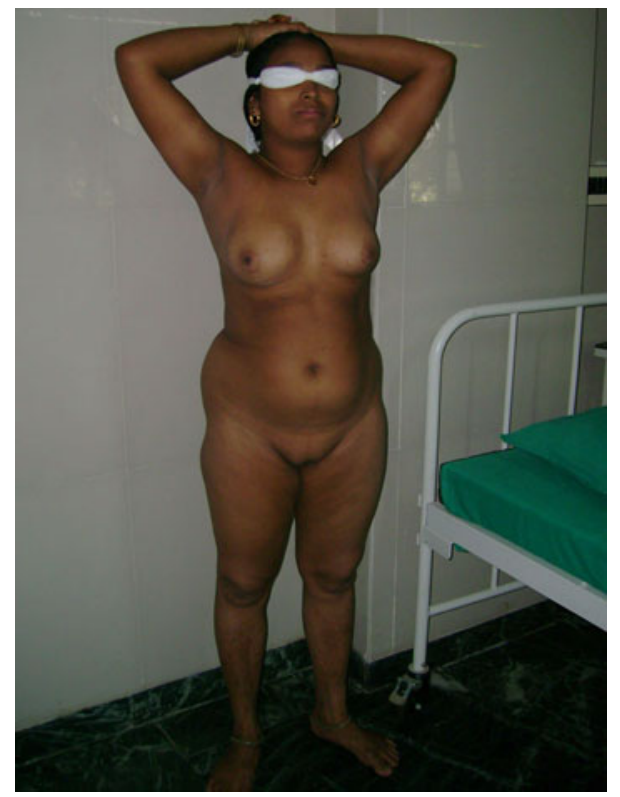

Fig. 1 External appearance: female, absent axillary and public hair, well-developed breasts present

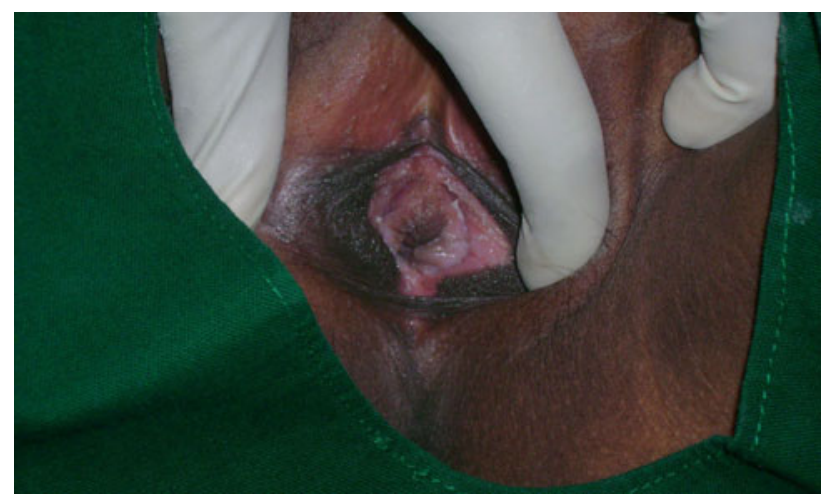

Fig. 2 External genitalia: female

After counseling, the patient was posted for surgery: bilateral gonadectomy with herniorrhaphy. Intraoperatively, the contents of the sac were gonads, a tubular remnant, and a fibromuscular band on both sides (Fig. 3). The histopathology report confirmed testicular tissue with smooth muscle fragments on both the sides (Fig. 4).

The postoperative period was uneventful. The patient was discharged on the 10th day. Estrogen replacement therapy with Tab. Premarin $0.625 \mathrm{mg}$ daily was advised.

\section{Discussion}

Androgen insensitivity syndrome is a rare disorder with an incidence of 1 in 20,000-99,000 in genetic males and a

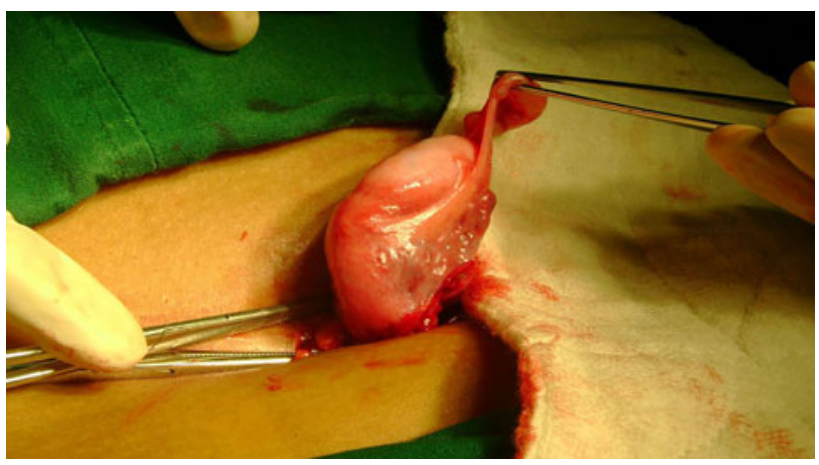

Fig. 3 Intraoperative appearance of the contents of the herniating sac on the left side: gonad, tubular structure, fibromuscular band

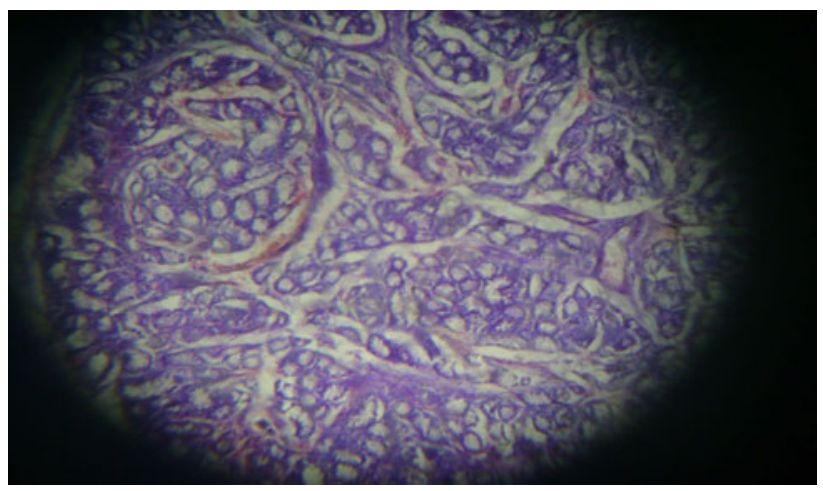

Fig. 4 Histopathology of gonad-testicular tissue

prevalence of $0.8-2.4 \%$ in phenotypic females with inguinal hernia [1]. The basic etiology is the loss of function-mutation in the androgen receptor gene. The affected individuals have $46 \mathrm{XY}$ karyotype, normal testes, normal production of testosterone, normal conversion to dihydrotestosterone, and a normal amount of anti-mullerian hormone. Thus, the uterus, cervix, fallopian tubes, and proximal vagina do not develop. In the fetal period, insensitivity to testosterone prevents masculinization of external genitalia. The lower $1 / 3$ of vagina develops as it originates from the urogenital sinus and presents as a blind vaginal pouch. There is an absence of axillary and pubic hair, lack of acne, and an absence of voice changes at puberty. The breasts are well developed due to conversion of testosterone to estradiol. The testes may be located anywhere along the path of embryonic testicular descent in the abdomen, inguinal canal, or labia. About $80-90 \%$ of individuals with CAIS develop inguinal hernia [1].

The testes in CAIS individuals cause pubertal feminization. Some studies have shown carcinomatous changes in the testes of the children of CAIS in the age group of 13-14 years and it is believed that testicular biopsy is 
warranted as soon as the syndrome is diagnosed. Recent studies reveal a tumor incidence (dysgerminoma, gonadoblastoma) of $0.8 \%$ in CAIS and $5.5 \%$ in AIS overall, and the risk increases markedly after puberty and reaches $33 \%$ at the age of $50[1,2]$. Thus, gonadectomy is advised after puberty. Once the testes have been removed, estrogen needs to be supplemented to maintain the external female form and to prevent osteoporosis and cardiovascular changes due to the deprivation of estrogen [1].

Studies have shown that individuals reported psychological trauma at diagnosis, which was compounded by their interaction with the medical care system [1]. During counseling, it was found that the patient was reared as a female and was leading a happy married life. Thus, informing the patient about the karyotype would be inadvisable and would have devastating psychological problems to the patient and the family. Therefore, they were informed that mullerian aplasia had occurred and the gonads were abnormally located, with chances of malignancy, and should be removed. The interaction and counseling of the affected individual and family require sensitivity and care.

\section{References}

1. Oakes MB, Eyvazzadeh AD, Quint E, et al. Complete androgen insensitivity syndrome- a review. J Pediatr Adolesc Gynecol. 2008;21:305-10.

2. Cools M, Drop SL, Wolffenbuttel KP, et al. Germ cell tumors in intersex gonad: old paths, new direction, moving frontiers. Endocr Rev. 2006;27:468-84. 